\title{
INFLUÊNCIA DO NÚMERO DE ESTÁGIOS NAS PROPRIEDADES FÍSICO-QUÍMICAS DAS FRAÇÕES DE BIOCOMBUSTÍVEIS OBTIDAS VIA DESTILAÇÃO FRACIONADA DO PRODUTO LÍQUIDO ORGÂNICO
}

\author{
C. C. FERREIRA ${ }^{1}$, O. A. CORRÊA ${ }^{1}$, J. G. EID ${ }^{1}$, A. A. MANCIO ${ }^{2}$ N. T. MACHADO ${ }^{3}$ \\ ${ }^{1}$ Universidade Federal do Pará, Programa de Pós-Graduação em Engenharia Química \\ ${ }^{2}$ Universidade Federal do Pará , Programa de Pós-Graduação em Engenharia de Recursos \\ Naturais da Amazônia \\ ${ }^{3}$ Universidade Federal do Pará, Dr-Ing do Programa de Pós-Graduação em Engenharia Química \\ E-mail para contato: caio.equi@yahoo.com.br
}

\begin{abstract}
RESUMO - O escopo principal deste trabalho está relacionado à investigação da influência do número de estágios (três, seis e nove estágios) em uma coluna do tipo Vigreux utilizada para o fracionamento do produto líquido orgânico (PLO). O procedimento experimental foi desenvolvido a fim de se obter quatro frações destiladas nas seguintes faixas de corte: (1) 40 a $175^{\circ} \mathrm{C}$, faixa de corte da gasolina verde; (2) 175 a $235^{\circ} \mathrm{C}$, faixa de corte do querosene verde; (3) 235 a $305^{\circ} \mathrm{C}$, faixa do diesel verde leve; (4) 305 a $400^{\circ} \mathrm{C}$, faixa do diesel verde pesado. As frações destiladas obtidas foram submetidas às análises físico-químicas (densidade, índice de acidez, viscosidade, índice de saponificação e ponto de fulgor), além da espectroscopia na região do infravermelho (IV). Ao analisar os resultados das análises físico-químicas, verificou-se que a maioria dos parâmetros se enquadra nas especificações da ANP. A análise química de infravermelho realizada sobre os produtos craqueados e destilados evidenciou a presença de compostos oxigenados, hidrocarbonetos parafínícos e olefínicos, cetonas e compostos aromáticos. A variação do número de estágios resultou em alterações para as propriedades físico-químicas, observando-se que ao aumentar o número de estágios os valores destas propriedades também aumentaram para a maioria das frações. Nas frações destiladas nas faixas de cortes do diesel leve e diesel pesado o aumento do número de estágios possibilitou a melhora da qualidade das mesmas.
\end{abstract}

\section{INTRODUÇÃO}

A crescente demanda da sociedade globalizada por energia, associada a legislações rigorosas de preservação ambiental no ocidente, assim como a crescente conscientização da sociedade pela preservação do meio ambiente e conservação dos estoques naturais, tem motivado o desenvolvimento de pesquisas com foco na produção de combustíveis provenientes de fontes renováveis, em substituição aos combustíveis de origem fóssil, os quais além de causarem impacto negativo no meio ambiente, devido aos elevados níveis de gases tóxicos tais como NOx e SOx, oxidantes fotoquímicos, compostos a base de enxofre, e material particulado na atmosfera, contribuem para o aquecimento global (RAMYA et al., 2002; . KATIKANENI et al., 1998).

A biomassa apresenta-se como uma alternativa de matéria prima renovável em varias rotas 
tecnológicas de produção de biocombustíveis, entre as quais destacam-se, os processo de trasesterificação, pirólise, gaseificação, e o craqueamento termo catalítico, que produzem combustíveis líquidos e gasosos, semelhantes aos combustíveis de origem fóssil, e portanto, capazes de substituí-los. Neste contexto, as perspectivas do utilização de biomassa como fonte natural de energia para a produção de biocombustíveis é uma alternativa viável e natural (ROSILLO-CALLE et al., 2005).

Dentre as diversas rotas tecnológicas de produção de biocombustíveis, destaca-se o craqueamento termo catalítico de óleos e gorduras de origem vegetal e animal. O craqueamento consiste na decomposição térmica e/ou catalítica dos óleos e gorduras, produzindo-se misturas de hidrocarbonetos nas diferentes faixas de combustíveis, além dos hidrocarbonetos formados, as moléculas dos triglicerídeos quebradas formam ácidos graxos, água e outros compostos orgânicos (PRADO e FILHO, 2009). Para fracionar/separar os componentes constituintes dessa mistura complexa, é necessário submeter à mistura líquida ao processo de destilação fracionada (GEANKOPLIS, 2008).

Fengwen Yu et al. (2013) investigaram a pirólise de óleo de soja utilizando catalisadores mesoporosos $\mathrm{Me}-\mathrm{Al}-\mathrm{MCM}-41(\mathrm{Me}=\mathrm{La}, \mathrm{Ni}$ ou $\mathrm{Fe}$ ). Os experimentos foram realizados num reator tubular a $450^{\circ} \mathrm{C}$. Os produtos de pirólise foram submetidos à destilação e denominados em gasolina verde $\left(\mathrm{t} \leq 50^{\circ} \mathrm{C}\right)$, diesel verde $\left(50^{\circ} \mathrm{C}<\mathrm{T}<150^{\circ} \mathrm{C}\right)$; e alcatrão $\left(\mathrm{T} \geq 150^{\circ} \mathrm{C}\right)$ sob vácuo de $100 \mathrm{~Pa}$. Já o craqueamento térmico de óleo de palma na faixa de temperatura de 300 a $400{ }^{\circ} \mathrm{C}$ foi investigado por Lima et al. (2004). Os produtos líquidos foram submetidos à destilação e separados em frações, obtendo-se frações físico-química compatíveis com as especificadas pelos combustíveis à base de petróleo.

Embora, a literatura cite estudos relacionados à destilação de produtos líquidos orgânicos obtidos via craqueamento termo catalítico de óleos vegetais (Fengwen Yu et al,; e Lima et al.), os mesmo focaram na análise composicional das frações de biocombustíveis via GC-MS. Neste contexto, o presente trabalho teve como objetivo principal investigar a influência do número de estágios nas propriedades físico-químicas das frações de biocombustíveis (gasolina verde, querosene verde, diesel leve verde e diesel pesado verde), obtidos/produzidos via destilação fracionada do produto líquido orgânico (PLO), utilizando-se uma Coluna Destilação Vigreux.

\section{MATERIAS e MÉTODOS}

\subsection{Materiais}

O Produto Líquido Orgânico (PLO), utilizado como material de alimentação no Processo de Destilação Fracionada foi produzido via Craqueamento Termo-Catalítico do Óleo de Palma (Elaeis guineensis Jacq) a $450{ }^{\circ} \mathrm{C}$, na Unidade Piloto de Craqueamento de Óleos Vegetais do TERMTEK-LEQ-UFPA, utilizando-se $20 \%(\mathrm{w} / \mathrm{w})$ de Carbonato de Sódio $\left(\mathrm{Na}_{2} \mathrm{CO}_{3}\right)$ como catalisador.

\subsection{Caracterização Físico-Química do Produto Líquido Orgânico e Frações de Biocombustíveis (Gasolina, Querosene, Diesel Leve e Diesel Pesado)}

O Produto Líquido Orgânico (PLO), assim como as frações de biocombustíveis obtidas via Destilação Fracionada nas faixas de temperatura $\left(40^{\circ} \mathrm{C} \leq \mathrm{T} \leq 175^{\circ} \mathrm{C}\right)$ (Gasolina Verde), $\left(175^{\circ} \mathrm{C} \leq\right.$ 
$\left.\mathrm{T} \leq 235^{\circ} \mathrm{C}\right)$ (Querosene Verde), $\left(235^{\circ} \mathrm{C} \leq \mathrm{T} \leq 305^{\circ} \mathrm{C}\right)$ (Diesel Verde Leve), $\left(305^{\circ} \mathrm{C} \leq \mathrm{T} \leq 400\right.$ ${ }^{\circ} \mathrm{C}$ ) (Diesel Verde Pesado), foram submetidas às análises físico-químicas no Laboratório de Análises Físico-Químicas do TERMTEK-LEQ-UFPA, de acordo com os Métodos Oficias de Análises AOCS e ASTM, em termos do Índice de Acidez (ASTM D 974), Índice de Saponificação (AOCS Cd 3-25), Índice de Refração através do ajuste do Refratômetro de Abbé com água destilada (IR $20^{\circ} \mathrm{C}=1.333$ ), de acordo com o Método AOCS Cc 7-25, utilizando-se o Refratômetro (Analytik Jena), acoplado ao banho termostático (Thermo Haake, Modelo C10, B6), Corrosividade em Lâmina de Cobre, de acordo com o Método ASTM D130, utilizando-se o equipamento (PETROTEST DP, Modelo: E 25-0600), Ponto de Fulgor, de acordo com o Método ASTM D92, utilizando-se o equipamento de vaso fechado (TANAKA, Modelo APM-7/FC-7), Modelo: E 25-0600), Densidade, de acordo com o Método do Picnômetro (ASTM D854 a $25^{\circ} \mathrm{C}$ ), Viscosidade, de acordo com o Método ASTM D 446, utilizando-se um Viscosímetro CannonFenske (Schot Geräte, Model: 520 23), com tubo capilar No. 100.

\subsection{Aparato Experimental (Unidade de Destilação Fracionada)}

O fracionamento do PLO para produção da gasolina verde, querosene verde, diesel leve e pesado verdes, foi realizado por destilação fracionada utilizando um aparato experimental, composto por uma manta de aquecimento elétrico de $315 \mathrm{~W}$ (Quimis, modelo: Q321A25/515), controlado por um termostato, um balão de fundo redondo de $1000 \mathrm{ml}$, balão de vidro com três bocas com junções externas de boro-silicato, $20^{\circ}, 24 / 40$, um lado utilizado para inserir um fino e longo termopar, com um termômetro digital e o outro para coletar amostras, 24/40 do centro, ligados a uma coluna de destilação (Vigreux), de boro-silicato, com variações de três, seis e nove estágios, acoplado a um condensador de Liebig de boro-silicato, com $700 \mathrm{~mm}$ de comprimento, acoplada a um funil de separação de vidro de boro-silicato, com capacidade de $230 \mathrm{ml}$, torneira de vidro 19/38, e um banho termostático (Quimis, modelo Q214M2).

\subsection{Procedimento Experimental}

O produto líquido orgânico (PLO) foi submetido à escala de laboratório de destilação fracionada, utilizando uma coluna Vigreux, variando o número de estágios em três, seis e nove. O PLO foi destilado dentro das faixas de temperatura de 40 a $175^{\circ} \mathrm{C}$, faixa de temperatura de destilação da gasolina verde; 175 a $235^{\circ} \mathrm{C}$, correspondente à faixa de temperatura de destilação do querosene verde; 235 a $305^{\circ} \mathrm{C}$, correspondente à faixa de temperatura de destilação do diesel verde leve; 305 a $400^{\circ} \mathrm{C}$, faixa de temperatura de destilação do diesel verde pesado. Todas estas frações produziram frações aquosas e frações orgânicas. As frações aquosas obtidas em cada faixa de temperatura de destilação foram coletadas e armazenadas, enquanto as frações orgânicas foram submetidas às análises físico-químicas, como descrito na secção 2.4 , de acordo com a literatura para combustíveis fósseis (THOMAS et al., 2001).

\section{RESULTADOS e DISCUSSÃO}

\subsection{Caracterização Físico-Química do Produto Líquido Orgânico}

A Tabela 1 ilustra os valores das propriedades físico-químicas, descritas na seção 2.2, do produto líquido orgânico (PLO). Observa-se que os valores das propriedades físico-químicas Densidade e Índice de Saponificação sofreram uma redução quando comparados com os valores 
apresentados pela ANVISA, para o Óleo de Palma Bruto, os quais estão na faixa de 0,891-0,899 $\mathrm{g} / \mathrm{cm}^{3}$ para a densidade e $190-209 \mathrm{mg} \mathrm{KOH} / \mathrm{g}$ para o Índice de Saponificação. Os baixos valores de ambas as propriedades físico-químicas para o PLO indicam que o craqueamento termocatalítico do óleo de palma foi eficiente em relação à conversão dos triglicerídeos em hidrocarbonetos.

Tabela 1 - Resultados das análises físico-químicas obtidas para o PLO

\begin{tabular}{ccc}
\hline Análises & Unidade & PLO \\
\hline Densidade $\left[\mathrm{g} / \mathrm{cm}^{3}\right]$ & $\mathrm{g} / \mathrm{cm}^{3}$ & 0,79 \\
Viscosidade a $40^{\circ} \mathrm{C}\left[\mathrm{mm}^{2} / \mathrm{s}\right]$ & $\mathrm{mm}^{2} / \mathrm{s}$ & 2,02 \\
Índice de Acidez $[\mathrm{mgKOH} / \mathrm{g}]$ & $\mathrm{mg} \mathrm{KOH} / \mathrm{g}$ & 1,02 \\
Índice de Saponificação & $\mathrm{mg} \mathrm{KOH} / \mathrm{g}$ de amostra & 14,35 \\
{$[\mathrm{mgKOH} / \mathrm{g}]$} & - & 1,44 \\
Índice de Refração & - & $1^{\mathrm{a}}$ \\
Corrosividade ao Cobre & ${ }^{\circ} \mathrm{C}$ & 85,1 \\
Ponto de Fulgor & &
\end{tabular}

O PLO é constituído basicamente por hidrocarbonetos e compostos oxigenados (OLIVEIRA, 2013). De acordo com os valores apresentados na Tabela 1 e com Farah (2012), tomando como base as propriedades físicas como densidade e viscosidade, os hidrocarbonetos que fazem parte do PLO, se enquadram na função química parafina, devido estas serem caracterizadas por hidrocarbonetos com densidade inferior a $0,85 \mathrm{~g} / \mathrm{cm}^{3}$ e apresentarem viscosidade relativamente baixa.

Quando comparado com outros trabalhos relatados na literatura, o valor de índice de acidez apresentado na Tabela 1 é relativamente baixo. Isso se deve ao fato do craqueamento em temperaturas mais altas ser mais severo, provocando a quebra dos produtos oxigenados e fazendo com que o craqueamento secundário das moléculas se efetue, originando produtos mais ricos em hidrocarbonetos. Quanto menor o teor de oxigênio nos produtos, menor será a acidez livre da amostra. Corrêa (2011) empregou o mesmo catalisador, porém em uma porcentagem diferente, $10 \%$ de carbonato de sódio, resultando na obtenção de um valor igual a $8,9 \mathrm{mg} \mathrm{KOH} / \mathrm{g}$ para o índice de acidez. Portanto, constatou-se que o incremento do catalisador carbonato de sódio, bem como as condições operacionais adotadas para o craqueamento termocatalítico do óleo de palma, resultaram na redução do índice de acidez. Este fato enfatiza a importância do craqueamento termocatalítico com carbonato de sódio, pois a maioria dos trabalhos relatados na literatura apresentam valores de índice de acidez relativamente altos como os valores de 77 a $141 \mathrm{mg}$ $\mathrm{KOH} / \mathrm{g}$ encontrados por Corrêa (2011) ao empregar vários tipo de catalisadores e os valores de 44,6, 82,7 e 90,8 mg KOH/g encontrados por Prado e Filho (2009) ao empregar a bauxita como catalisador.

\subsection{Caracterização Físico-Química das Frações Destiladas}

As figuras 1 a 4 apresentam os resultados obtidos para as análises físico-químicas (Densidade, Viscosidade, Índice de Acidez e Ponto de Fulgor) das seguintes frações: Gasolina Verde, Querosene Verde, Diesel Verde Leve e Diesel Verde Pesado.

De acordo com a Figura 1, observou-se que os valores para as frações na faixa de corte do 
querosene e diesel pesado estão dentro dos limites especificados pela ANP $\mathrm{n}^{\circ} 37$ e 65 , os quais estão na faixa de 0,771-0,837 e 0,82 - 0,85, respectivamente. Analisando o efeito do número de estágios da coluna Vigreux sobre as frações destiladas, verifica-se que não houve mudanças significativas nos valores da densidade. Porém, são notórios os aumentos das densidades com o aumento das faixas de temperatura de destilação. Isto pode ser explicado pelo aumento no número de carbonos dos hidrocarbonetos em cada faixa de temperatura de destilação, pois quanto maior a cadeia de hidrocarbonetos, maior será sua densidade. Os resultados obtidos estão de acordo com Ferreira et al. (2012) e Oliveira (2013), o primeiro encontrou a mesma fração na faixa de corte da gasolina numa coluna com três estágios, que foi de $0,69 \mathrm{~g} / \mathrm{cm}^{3}$; já o segundo destilou na faixa de corte do querosene, e também os valores estão dentro das especificações da ANP do querosene de petróleo, este numa coluna Vigreux com seis estágios.

Em relação à Figura 2, os valores da viscosidade apresentam efeitos significativos quando se altera a faixa de temperatura de corte, resultando em um aumento gradativo à medida que a faixa de temperatura de corte aumenta. $\mathrm{O}$ número de estágios apresentou influências significativas nos valores de viscosidade, em que quanto maior o número de estágios menor a viscosidade da fração na faixa de corte do diesel pesado, porém, maior a viscosidade da fração na faixa de corte da gasolina. Isto pode ser explicado por uma elevação na concentração de hidrocarbonetos de cadeia longa da fração na faixa de corte da gasolina e uma redução na concentração de hidrocarbonetos de cadeia longa na fração com faixa de corte correspondente ao diesel pesado. As frações na faixa de corte do diesel pesado se enquadram dentro dos limites estabelecidos pela ANP $\mathrm{n}^{\circ}$ 65. Já as frações destiladas com faixas de temperaturas menores, a norma sugere para anotar os valores, haja vista que não há especificações. Os resultados obtidos estão de acordo com Oliveira (2013), este encontrou $0,7353 \mathrm{~mm}^{2} / \mathrm{s}$ na faixa de corte do querosene e $1,8384 \mathrm{~mm}^{2} / \mathrm{s}$ na faixa de corte do diesel, ambos os resultados na coluna de seis estágios.
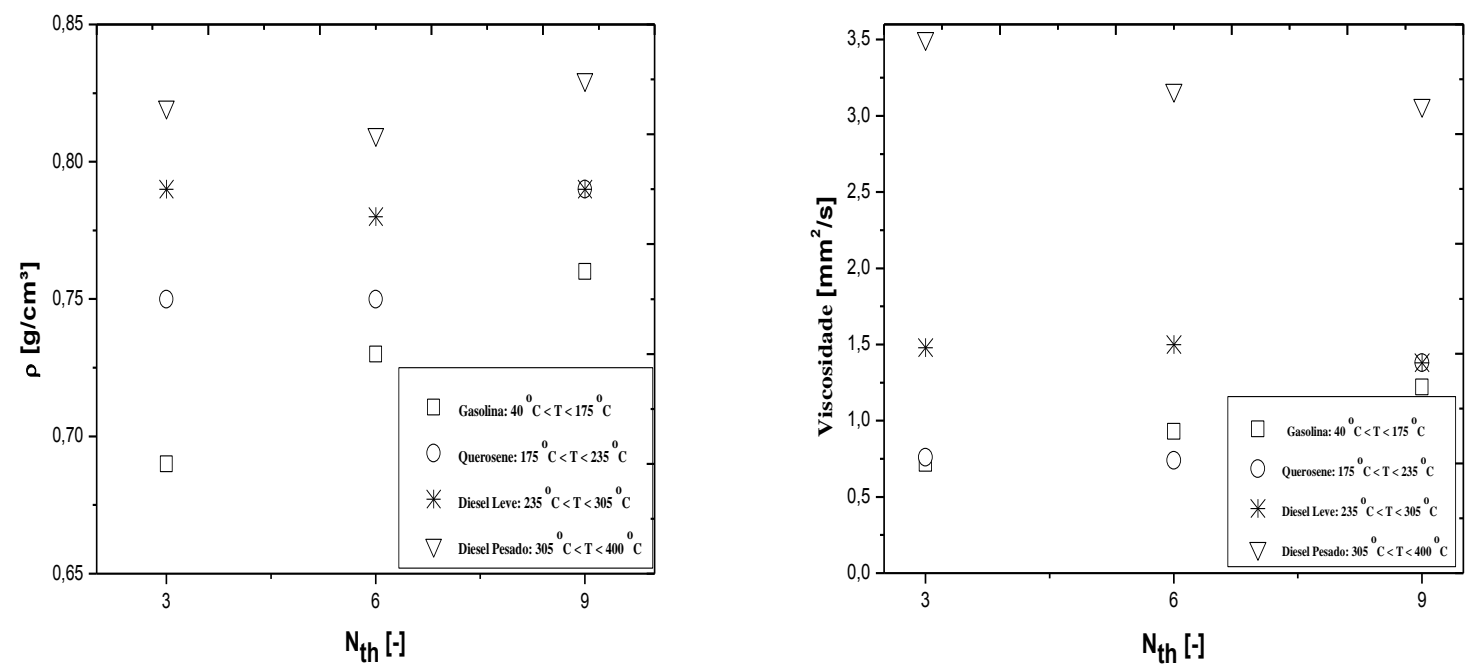

Figura 1 - Densidade das frações destiladas. Figura 2 - Viscosidade das frações destiladas.

Ao analisar a Figura 3, percebe-se que há uma tendência de redução definida na faixa de corte do diesel pesado quando se aumenta o número de estágios para o índice de acidez. Fazendo uma comparação do índice de acidez das frações mais leves (frações na faixa de corte da gasolina e querosene) com o índice de acidez do produto obtido no craqueamento termocatalítico, que foi 
de 1,02 mg KOH/g, nota-se uma diminuição da acidez. Os resultados obtidos estão de acordo com Oliveira (2013), este encontrou $1,3148 \mathrm{mgKOH} / \mathrm{g}$ na faixa de corte do querosene e 0,3936 $\mathrm{mgKOH} / \mathrm{g}$ na faixa de corte do diesel, ambos na coluna de seis estágios.

A vaporização adequada de um combustível pode ser traduzida por algumas propriedades euma delas é o ponto de fulgor. De acordo com Farah (2012) o ponto de fulgor é aplicado a derivados do petróleo médios e pesados, sendo inversamente proporcional a presença de frações leves. Portanto, de acordo com a Figura 4 pode-se dizer que as frações na faixa de corte do diesel leve e diesel pesado obtidas na coluna Vigreux com três estágios apresentam um teor maior de frações leves. Em contrapartida, as mesmas frações apresentam teores reduzidos de frações leves quando obtidas na coluna Vigreux com seis e nove estágios. Além disso, tem-se que os pontos de fulgor das frações destiladas obtidas em colunas com maior número de estágios estão dentro das faixas especificadas do diesel de petróleo, pela norma da ANP ${ }^{\circ} 65$, a qual especifica que o limite é acima de $38^{\circ} \mathrm{C}$. Para as frações destiladas na coluna com três estágios, os valores apresentaramse fora dos limites estabelecidos pela mesma norma, entretanto um blend em pequena porcentagem entre o produto obtido e um diesel de petróleo ou entre o produto e um biodiesel pode adequar esta propriedade aos parâmetros estabelecidos.

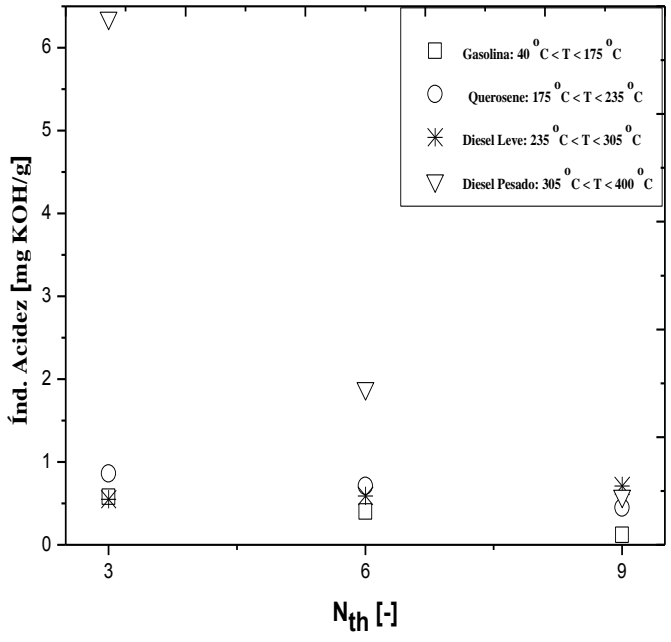

Figura 3 - Acidez para as frações destiladas.

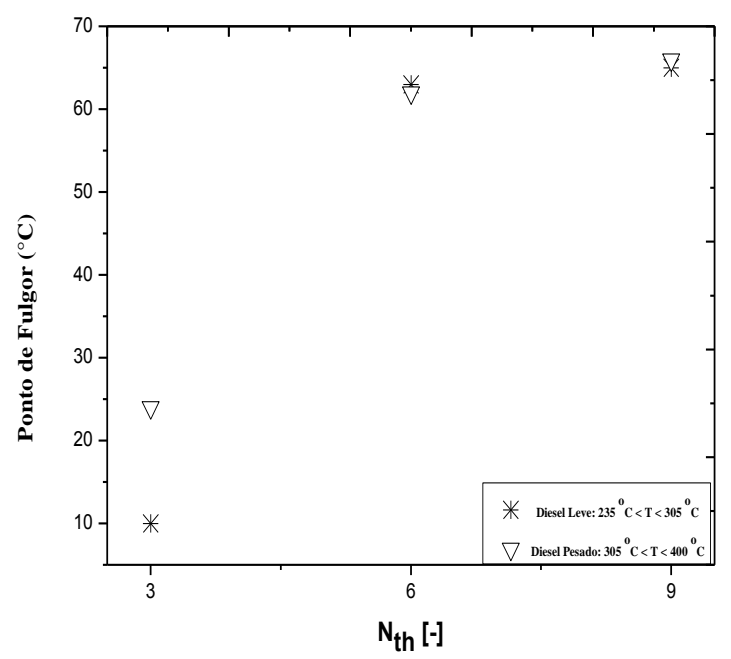

Figura 4 - Ponto de Fulgor das frações destiladas.

\subsection{Espectros do PLO e das Frações Destiladas}

Nos espectros de infravermelho apresentados abaixo para o PLO e frações destiladas na coluna de três e seis estágios, Figuras 5 e 6 , foram identificadas a presença de bandas correspondentes à deformação axial de O-H dos dímeros de ácidos carboxílicos e fenóis (3600 $3200 \mathrm{~cm}^{-1}$ ), sendo confirmadas pela presença de bandas de deformação axial de C-H da alquila superpostas à banda larga de O-H nas seguintes faixas de picos: $2926-2918 \mathrm{~cm}^{-1}, 2852-$ $2848 \mathrm{~cm}^{-1}$, assim como, as bandas entre $1300-1000 \mathrm{~cm}^{-1}$ correspondentes às ligações C-O. Notou-se também que as bandas correspondentes aos ácidos carboxílicos entre $1720-1706 \mathrm{~cm}^{-1}$, o modo de deformação angular de C-O-H possibilitou a identificação de bandas na faixa de 1460 $1458 \mathrm{~cm}^{-1}$ correspondendo ao grupo funcional aldeído. Os picos de 1159 a $810 \mathrm{~cm}^{-1}$ correspondem 
às bandas de alcanos de vibrações axiais de C-C, que aparecem compreendidas entre 1200 e 800 $\mathrm{cm}^{-1}$. Por último, os picos correspondentes às faixas de $634-540 \mathrm{~cm}^{-1}$ são caracterizadas como sendo vibrações de deformações angular fora do plano de $\mathrm{C}-\mathrm{H}$ de hidrocarbonetos aromáticos.

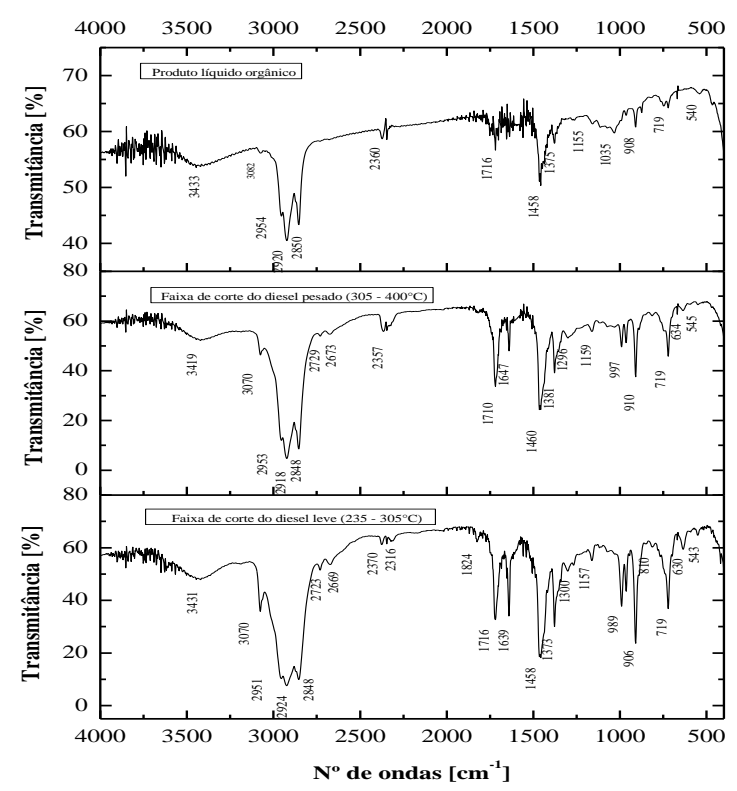

Figura 5 - Espectros do PLO, Diesel leve e pesado para 3 estágios.

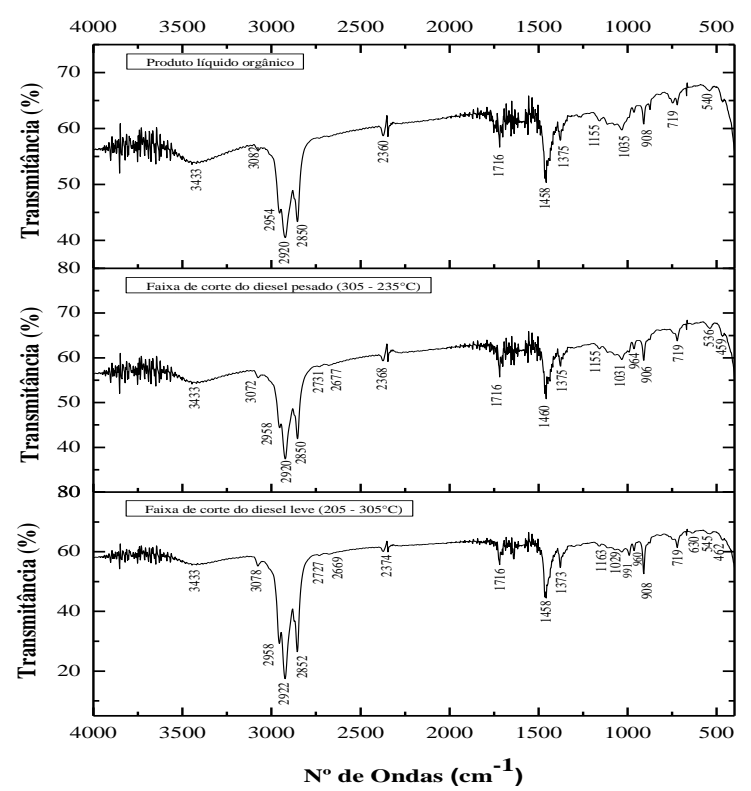

Figura 6 - Espectros do PLO, Diesel leve pesado para 6 estágios.

\section{CONCLUSÃO}

Este trabalho investigou a influência do número de estágios (três, seis e nove estágios) em uma coluna do tipo Vigreux utilizada para o fracionamento do produto líquido orgânico (PLO). Os resultados mostram que o parâmetro densidade das frações aumenta quando se eleva o número de átomos de carbono da cadeia de hidrocarbonetos, mas não se altera com o aumento da coluna. Em relação à viscosidade percebe-se que com o aumento do número de estágios a temperatura de corte da gasolina aumenta, mas ocorre a diminuição na temperatura de corte da fração do diesel pesado com o aumento do número de estágios. Ao analisar o índice de acidez notou-se que este parâmetro foi reduzindo das frações destiladas na temperatura de corte da gasolina até a temperatura de corte do diesel leve quando comparamos com o PLO obtido. A exceção é o aparecimento do alto valor do índice de acidez na temperatura de corte da fração destilada do diesel pesado para os estágios de nove e principalmente o de três, evidenciando uma maior concentração de ácidos graxos nessas frações. Em relação ao ponto de fulgor as temperaturas de cortes das frações do diesel leve e pesado se encontraram dentro da norma da ANP para os estágios quatro, seis e nove. A exceção é para as frações obtidas na coluna de três estágios, as quais apresentaram valores inferiores aos estabelecidos pela norma. Desta forma, concluiu-se que os parâmetros densidade, viscosidade e ponto de fulgor se enquadram nas especificações da ANP para a maioria das frações destiladas, indicando que as frações destiladas se mostraram de boa qualidade para tais parâmetros.

As análises dos espectros realizadas sobre o produto craqueado e as frações destiladas (diesel leve e pesado) evidenciaram a presença de compostos oxigenados (ácidos carboxílicos), 
hidrocarbonetos parafínícos (alcanos) e hidrocarbonetos olefínicos (alquenos), cetonas e compostos aromáticos.

\section{REFERÊNCIAS}

CORRÊA, I. M. R. Estudo do processo de destilação do produto craqueado do óleo de palma (Elaeis guineensis jacq) em escala de bancada. 2011. 50 f. Trabalho de Conclusão de Curso - Universidade Federal do Pará, Belém, 2011.

FARAH, M.A. Petróleo e seus derivados: definição, constituição, aplicação, especificações, características de qualidade. Rio de Janeiro: Livros Técnicos e Científicos -LTC, 2012.

FENGWEN YU. et al. Bio-fuel production from the catalytic pyrolysis of soybean oil over Me-Al-MCM-41 (Me = La, Ni or Fe) mesoporous materials. Journal of Analytical and Applied Pyrolysis, v. 104, p. 325-329, november. 2013.

FERREIRA, R.K. Estudo Comparativo do Processo de Destilação Simples e Fracionado em Escala de Bancada. $7^{\circ}$ Congresso Nacional de Bioenergia. Belém/Pa, <www.portal.ufpa.br, cmeq@ufpa.br>, (91)3201-7848

GEANKOPLIS, C. J. Procesos de Transportes y Operaciones Unitarias. 3 ed. México: Compañia Editorial Continental, S.A. de C.V., 2008.

KATIKANENI, S. P. R. et al. Performance studies of various cracking catalysts in the conversion of canola oil to fuels and chemicals in a fluidized-bed reactor. Journal of the American Oil Chemists Society, v. 75, p. 381-391, 1998.

LIMA et al. Diesel-like fuel obtained by pyrolysis of vegetable oils. Journal of Analytical and Applied Pyrolysis, v. 71, n. 2, p. 987-996, 2004.

OLIVEIRA, R.M. Estudo da obtenção de biocombustíveis a partir da rota tecnológica de craqueamento utilizando carbonato de sódio e lama vermelha como catalisadores. 2013. $118 \mathrm{f}$. Dissertação (Mestrado em Engenharia Química) - Instituto de Tecnologia, Universidade Federal do Pará, Pará. 2013.

PRADO, C. M. R.; FILHO, N. R. A. Production and characterization of the biofuels obtained by thermal cracking and thermal catalytic cracking of vegetable oils. J. Anal. Appl. Pyrolysis, p. 338-347, 2009.

RAMYA, G. Liquid hydrocarbon fuels from jatropha oil through catalytic cracking technology using AlMCM-41/ZSM-5 composite catalysts. Applied Catalysis A: General, v. 433434, p. 170-178, 8 August. 2012.

ROSILLO-CALLE, F.; BAJAY, S. V.; OTHMAN, R. H. Uso da biomassa para produção de energia na indústria brasileira. Campinas, SP: Editora da Unicamp, 2005.

THOMAS et al. Fundamentos de Engenharia de Petróleo. Rio de Janeiro: Editora Interciência, 2001. 